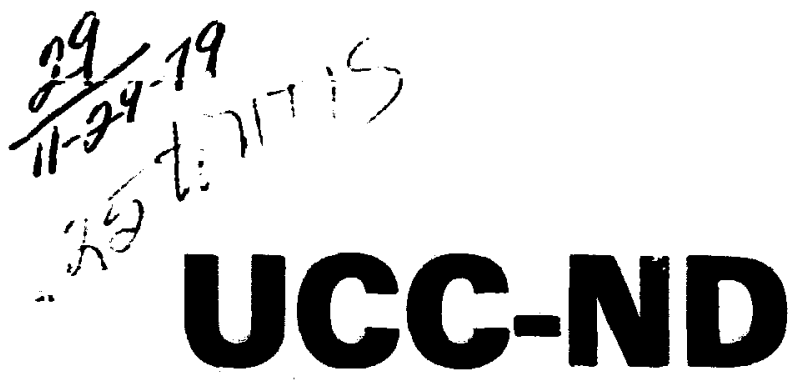

ORNL/CSD/TM-78

\title{
NUCLEAR \\ DIVISION
}

UNHON

CARBIDE

\section{Numerical Determination of Inert Gas Permeability Parameters of High- Temperature $\mathbf{G}$ as-Cooled Reactor (HTGR) FuelParticles}

J. S. Tolliver

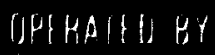

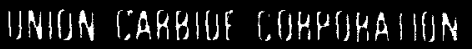
HJP IHE. UNITEUS SIAIS:, 
ORNL/CSO/TM-78

Contract No. H-7405 eng 26

Computer Sciences Division

NUMERICAL DETERMIMATION OF INERT GAS PERMEABILITY PARAMETERS

OF HIGH-TEMPERATURE GAS-COOLED REACTOR (HTGR) FUEL-PARTICLES

J. S. Tolliver

Sponsor: C. S. Morgan

Originator: J. S. Tolitiver

Date Published: November 1979

wotef This document contuin information of o preliminary noture. It is eubject to rovision or correction and therefore dose mor represents final report.

UNION CARBIDE CORPORATION, NUCLEAR DIVISION operating the

Oak Ridge Gaseous Diffusion Plant Oak Ridge National Laboratory Oak Ridge $Y-12$ Plant Paducah Gaseous Diffusion Plant for the DEPARTMENT OF ENERGY

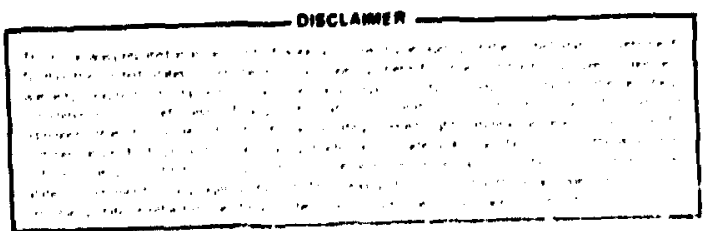


TABLE OF CONTENTS

List of figures ................ List of iables ........................ vii

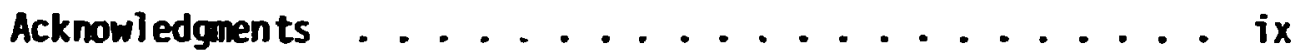

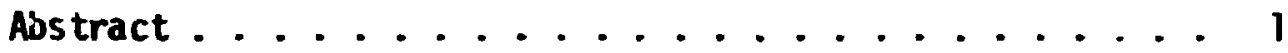

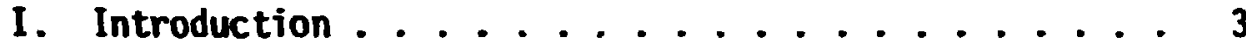

II. Theoretical Results and Data-Fitting Procedure .............. 5

III. Results ................ 7

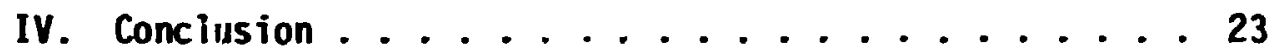

v. References .............. 25 


\section{LIST OF FIGURES}

Fig. la. Experimentai Uptake Data and Fitted Curve for OR2261HT Fuel-Particles Annealed in $\mathrm{Hel}$..m at $850^{\circ} \mathrm{C} \ldots . . .8$

Fig. 1b. Small Time Behavior of OR2261HT Helium Uptake Data

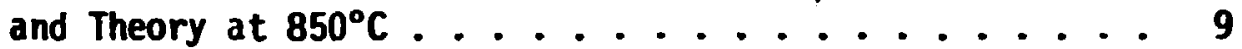

Fig. 2. Experimental Data and Fitted Curve for OR2261HT Fuel-Particles Annealed in Helium at $450^{\circ} \mathrm{C} \ldots \ldots$

Fig. 3. Plot of $2 n$ D vs. I/RT with Least Squares Line Fit Showing the Correctness of the Arrienius Relationship for 0R2261HT Data .............. 12

Fig. 4a. Experimental Data and Fitted Curve for 3596 Fuel-Particles Annealed in Hel iun at $550^{\circ} \mathrm{C} \ldots \ldots$

Fig. 4b. Experimenial Data and Fitted Curve for $\mathbf{J 5 9 8}$ Fuel-Particles Annealed in Helium at $550^{\circ} \mathrm{C} \ldots \ldots$. . . i7 


\section{LIST OF TABLES}

Table 1. Fitted Fuel-Particle Parameters D, $n$, and $s$ for OR2261HT Particles Annealed in Helium at $98 \mathrm{KPa} \ldots . . .11$

Table 2. Fitted Diffusivities and Porosities for Additional Experimental Measurements of Refs. 4 and $5 \ldots 14$

Table 3. Arrhenius Coefficients, Activiation Energies, and Averaged Porosities .............. 15

Table 4. Fitted Outer Porosity $n$ While Holding All Other Parameters Constant ............. 19

Table 5. Arrhenius Coefficients, Activation Energies, and Averaged Porosities After the Final Fit . . . . . . 20 


\section{ACKMOMLEDGMENTS}

Funding for this project was provided by the Gas Cooled Reactor Base Technology Program. Special thanks are due M. Reeves and G. L. Powell for their many helpful coments during the progran developinent and subsequent interpretation of the results. Thanks also are due C. K. Bayne for his discussions concerning the statistical interpretation of the results and C. E. Coek and P. A. Mcloy for their time and taient in preparing this report for publication. 


\section{ABSTRACT}

The high temperature diffusion of iriert gases through an outer layer of dense curbon into the $\mathrm{ThO}_{2}$ core of biso-coated High-Temperature Gas-Cooled Reactor (HTGR) fuel-particles is studied numerically. A mathematical model of diffusion through a dense spherical shell into a spherical core is used to numerically calculate the theoretical gas content of the core. This theoretical calculation, in tandem with an optimizing computer code and experimental data, is used to determine the diffusion coefficient of the shell and the porosities of the shell and inner core. The activation energy is also determined for use in an Arrhenius relationship between the diffusion coefficients and absolute temperature. 


\section{INTRODUCTION}

Biso-coated fuel-particles, consisting of an inner core of $\mathrm{ThO}_{2}$ fuel, a huffer layer of porous carbon, and an outer layer of dense carbon, are being developed at Oak Ridge National Laboratory (ORIL) for use in High-Temperature Gas-Cooled Reactors (HTGRs). The dense outer coating serves as a pressure vessel to retain gaseous fission products and to provide mechanical strength. The high-temperature inert gas permeability of the fuel-particles is of interest and has been studied experimentally by c. S. Morgan et al. of the Metal and Ceram.es Division of ORRL and G. L. Powell of the Oak Ridge Y-12 Plant Development Division. ${ }^{2-5}$ The mathematical aspects of the problem have been reported by Reeves and Tolliver. ${ }^{6}$ A computer code which calculates the theoretical gas content of the inner core is combined with a data-fitting program to obtain the best theoretical fit to experimental measurements of the gas content of HTGR fuel-particles. The present paper provides a brief discussion of the computer program and the results obtained from it. 


\section{THEORETICAL RESULTS AND DATA-FITTING PROCEDURE}

The theoretical expression obtained by Reeves and Tolliver ${ }^{6}$ for the gas content of the spherical core of a dense spherical shell is given below. Here, and in the equations to follow, $a$ and $b$ respectively denote the inner and outer radii of the spherical shell, $s$ and $n$ respectively denote the porosities of the inner core and outer shell, co is the constant concentration of gas surrounding the shell, and $D$ is the diffusion coefficient of the shell. Then the gas content or uptake $U$ as a function of time is given by

$$
U(t)=\gamma \bar{U}(t)
$$

where

$$
\begin{gathered}
\gamma=\frac{4}{3} \pi a^{2} b c_{0} s \\
\bar{u}(t)=\frac{a}{b}-\sum_{j=1}^{\infty} g\left(\alpha_{j}, 0 j e^{-D \alpha_{j}{ }^{2} t}\right. \\
g(a, 0)=\frac{2 a}{\alpha a(2 q+l) \sin \alpha^{7}} \frac{2 u}{+\left(a^{2} q a l-b\right) \cos \alpha \tau} \\
\tau=b-a \\
q=8 a / 3 n
\end{gathered}
$$

ind the $\alpha$ 's are the positive solutions to

$$
\tan \alpha z=\frac{\alpha a}{\alpha^{2} q a-1}
$$

For constant geometry the $\alpha^{\prime}$ s depend only on the ratio $q$ so the uptake $U$ can be uniquely specified by the three parameters $D, \gamma$, and $q$ 

plus, of course, the radi $i a$ and $b$ and the outside gas concentration $c_{0}$. The porosities $n$ and $s$ are easily obtained from the parameters $\gamma$ and $q$ as can be seer: from the definitions in Eqs. (2a) and (2e).

A computer program has been developed to calculate the theoretical uptake as a function of time from Eqs. (1) and (2) when given values for the three parameters $D, \gamma$, and $q$ and the geometric constants $a$ and $b$ along with the outs ide gas concentration $c_{0}$. In practice, the outside pressure $P$ is more easily known and maintained than the concentration so the relation

$$
c_{0}=\mathrm{KP} / \mathrm{T}
$$

is used to calculate $c_{c}$ in moles $/ \mathrm{m}^{3}$ from the pressure $P$ measured in kilnpascals and the absolute temperature $T$. The conversion factor is

$$
K=1.203 \times 10^{2} \mathrm{~mole}^{\circ}{ }^{\circ} \mathrm{Kelvin} / \mathrm{m}^{3} / \mathrm{kilopascal} .
$$

The uptake calculation has been incorporated into an optimization progr am which varies the parameters $D, \gamma$, and $q$ to minimize the chi-squared function for the uptake. Chi-squared is the function

$$
x^{2}=\sum_{n=1}^{N}\left[\frac{U_{n}-\hat{U}_{n}}{\delta_{n}}\right]^{2},
$$

where $U_{n}, \hat{U}_{n}$, and $\delta_{n}$ are, respectively, the theoretical uptake, experimentally measured uptake, and the experimental error for each of $\| J$ data points. The program returns the values of the parameters $D: \gamma$, and $q$ which yield the minimum chi-so'jared. From $\gamma$ and $q$, the porosities $n$ and $s$ are determined. 


\section{RESULTS}

Experimental measurements by Powel!" of the helium content of the inner corp of HTG fuel-particle batch OR2261HT have been used as input to the data-fitting procedure. Figure ?a shows the experimental data and the theoretical fit along with experimental error bars for the OR2261HT particles annealed in helium at $850^{\circ} \mathrm{C}$ at a pressurc of $98 \mathrm{KPa}$. Evident.ly, the theoretical fit is very good, falling well within the error bars at all times. Figure $1 \mathrm{~b}$ shows the behavior of the same data at small times. Figure 2 shows the results for a helium anneal at the same pressure but at i temperature of only $450^{\circ} \mathrm{C}$. The diffusion here is mur.h slower; the uptake did not reach its asymptotic value even after more than $\mathbf{4 0}$ days of diffusion. The theoretical fit for this case is not as good as for the $850^{\circ}$ case for at least two reasons. First, the physical model ised to sharacterize the diffusion may not adequately explain all of the details af the diffusion process at high and low extremes of temperature where the diffusion is either very fast or very slow. More likely, however, the problems involved with maintaining such an experiment for more than 40 days and the problems of accurately measuring the small quantities of gas present at small times contribute to less than ideal data. Since our model differs from a first-order approximation prima:ily at small tines (see Ref. 6), it is evident that the small time regime is of critical importance to the determination of the theoretical fit. Table I shows the results, that is, the diffusivities $D$ and the porosities $n$ and 8 , for a range of temperatures extending from $450^{\circ}$ to $1425^{\circ} \mathrm{C}$ for the OR2261HT fuelparticles. The rather large variabilicy in $n$ is of some concern and will be discussed later. 


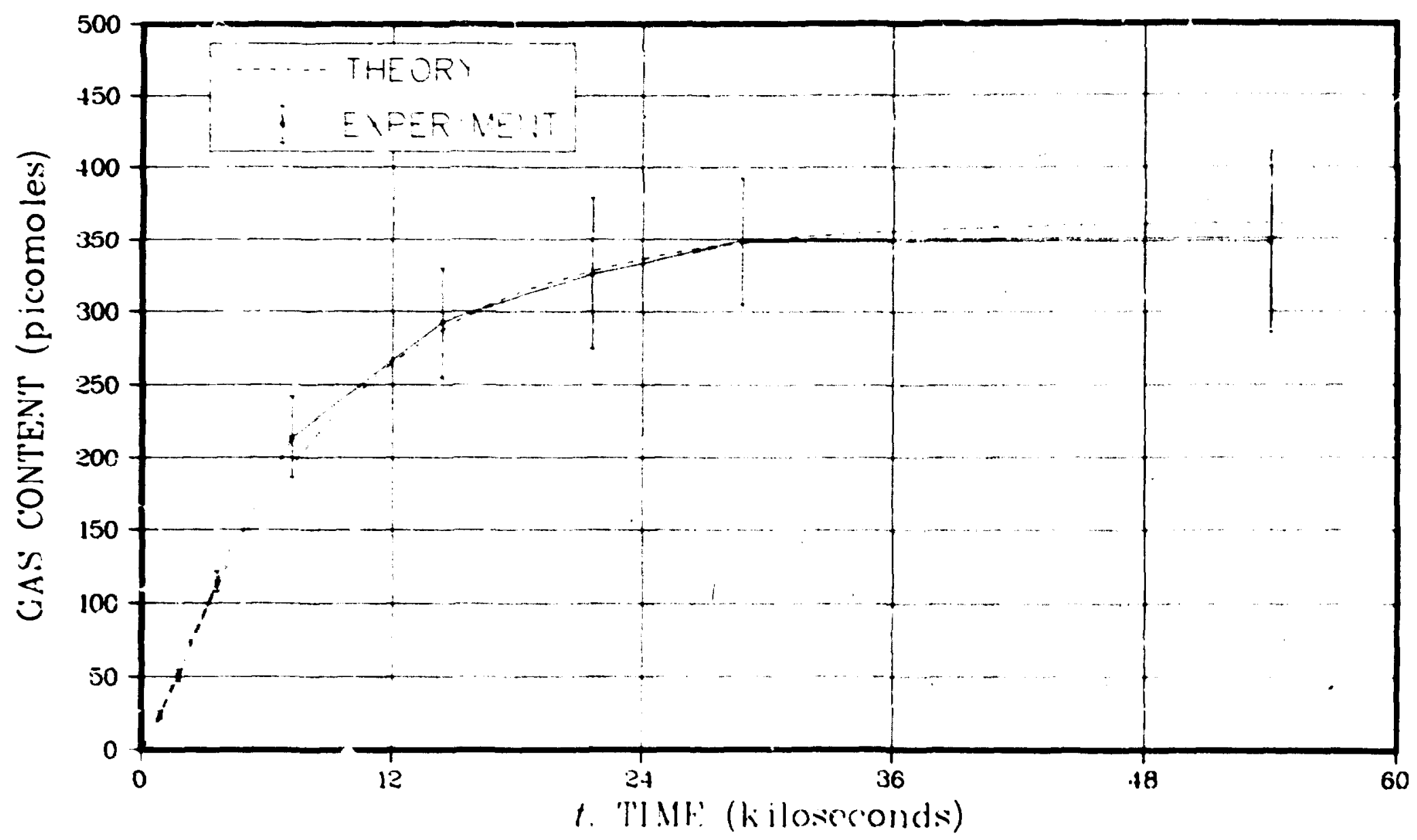

$\infty$

Fig. 1a. Experimental Uptake Data and Fitted Curve for OR2261HT Fuel-Particles Annealed in Heli'sm at $850^{\circ} \mathrm{C}$. 


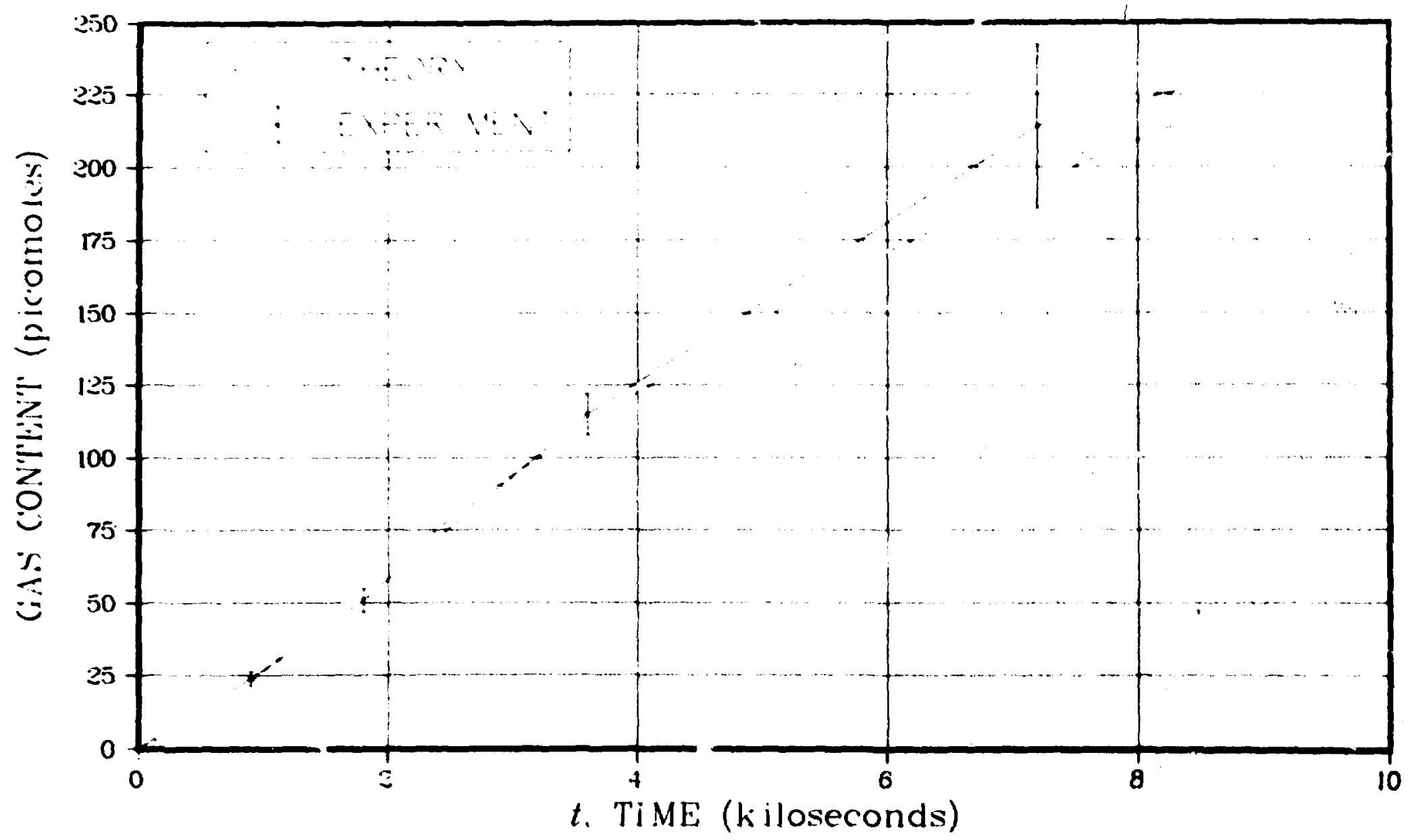

Fig. Ib. Sma?l Time Behavior of OR2261HT Helium Uptake Data and Theory at $850^{\circ} \mathrm{C}$. 


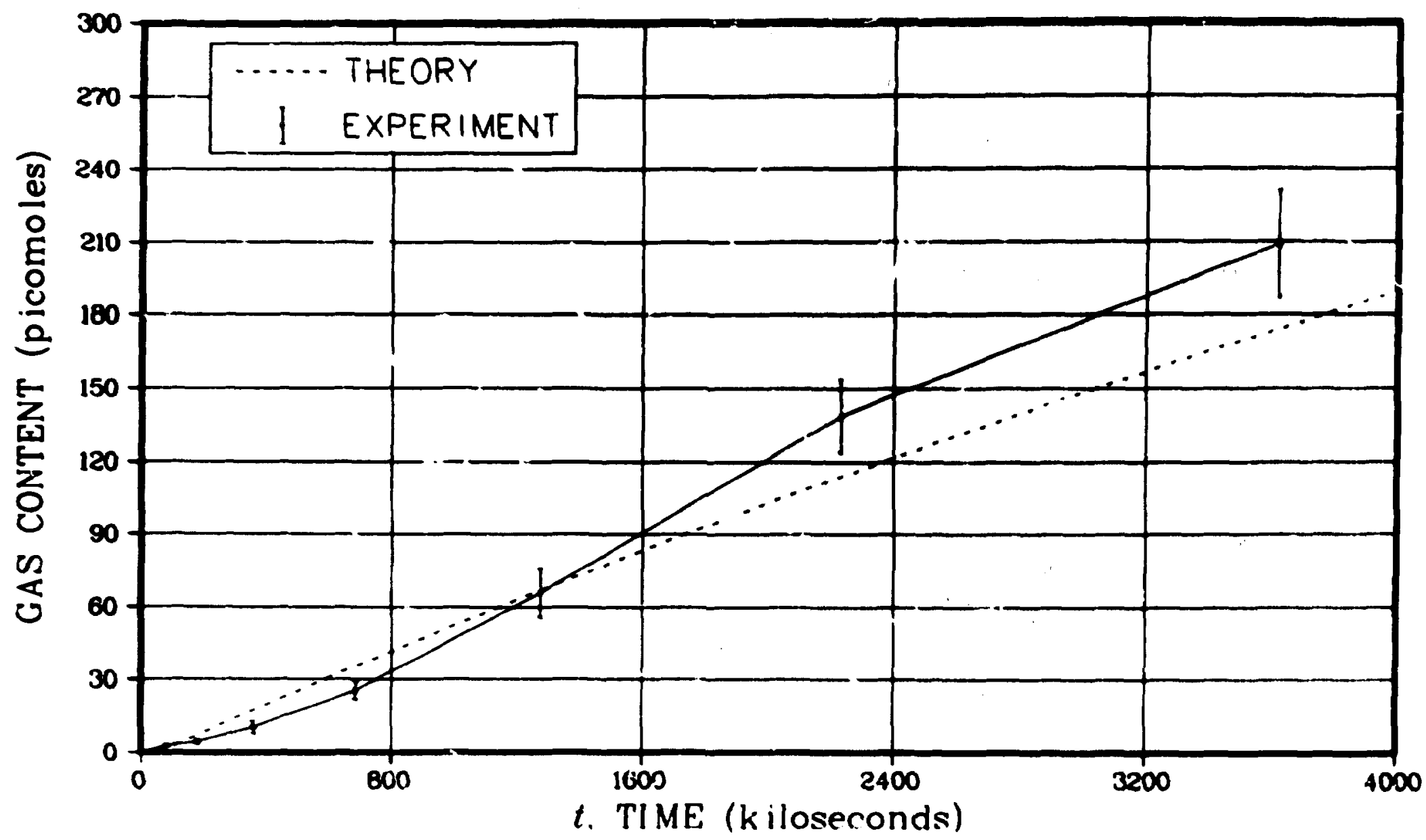

Fig. 2. Experimental Data and titted Curve for OR2261HT Fuel-Particles Annealed in Helium at $450^{\circ} \mathrm{C}$. 
Table 1. Fitted Fuel-Particle Parameters $D, n$, and $s$ for OR2261HT Partic.es Annealed in Helium at $98 \mathrm{KPa}$

\begin{tabular}{rccc}
\hline$T\left({ }^{\circ} \mathrm{C}\right)$ & $D\left(\mathrm{~m}^{2} / \mathrm{s}\right)$ & $n\left(\mathrm{~m}^{3} / \mathrm{m}^{3}\right)$ & $\varepsilon\left(\mathrm{m}^{3} / \mathrm{m}^{3}\right)$ \\
\hline 450 & $2.162 \times 10^{-16}$ & 0.00781 & 01942 \\
550 & $6.086 \times 10^{-14}$ & 0.0329 & 0.1947 \\
653 & $2.750 \times 10^{-13}$ & 0.0493 & 0.1947 \\
750 & $1.300 \times 10^{-12}$ & 0.0463 & 0.1946 \\
850 & $4.055 \times 10^{-12}$ & 0.0471 & 0.1948 \\
1000 & $1.922 \times 10^{-11}$ & 0.0455 & 0.1872 \\
1200 & $7.181 \times 10^{-10}$ & 0.0611 & 0.1905 \\
1425 & $9.412 \times 10^{-10}$ & 0.332 & 0.1950 \\
\hline
\end{tabular}

If one assumes that the diffusivities obey an Arrhenius relationship

$$
D=D_{0} e^{-Q / R T}
$$

with the activation energy $Q$ and absolute temperature $T$, then the points on In D vs. I/RT should fall on a straight line. A least squares fit made to the data produces the results shown in Fig. 3. Evidently, the Arrhenius relationship is obeyed except at the high and low temperatures. The data at the low end, $450^{\circ} \mathrm{C}$, is alreadij suspiect as mentioned earlier, and the high temperature data, at $1425^{\circ} \mathrm{C}$, consisted of only two data points so the results there are not entirely meaningful. Accordingly, the first and last data points, indicated by are rejected from the least squares fit and 211 further considerations. The fit yields a standard deviation of 0.108 anc the ronstants $\ln D_{0}=-14.228 \mathrm{~m}^{3} / \mathrm{sec}, \sigma_{2 n D_{0}}=0.230^{\circ}$ ind $Q=111.66$ kilojoules/mole- ${ }^{\circ}$ Kelvin, $\sigma_{Q}=2.06$.

Other measurements by "owel14 include the neon uptake of OR2261HT fuel-particles and the helfum uptake of OR2261HT particles that had received an extra 48 -hour vacuum anneal at $2000^{\circ} \mathrm{C}$ to remove process argon 
ORNL-DWG, 78-2]467

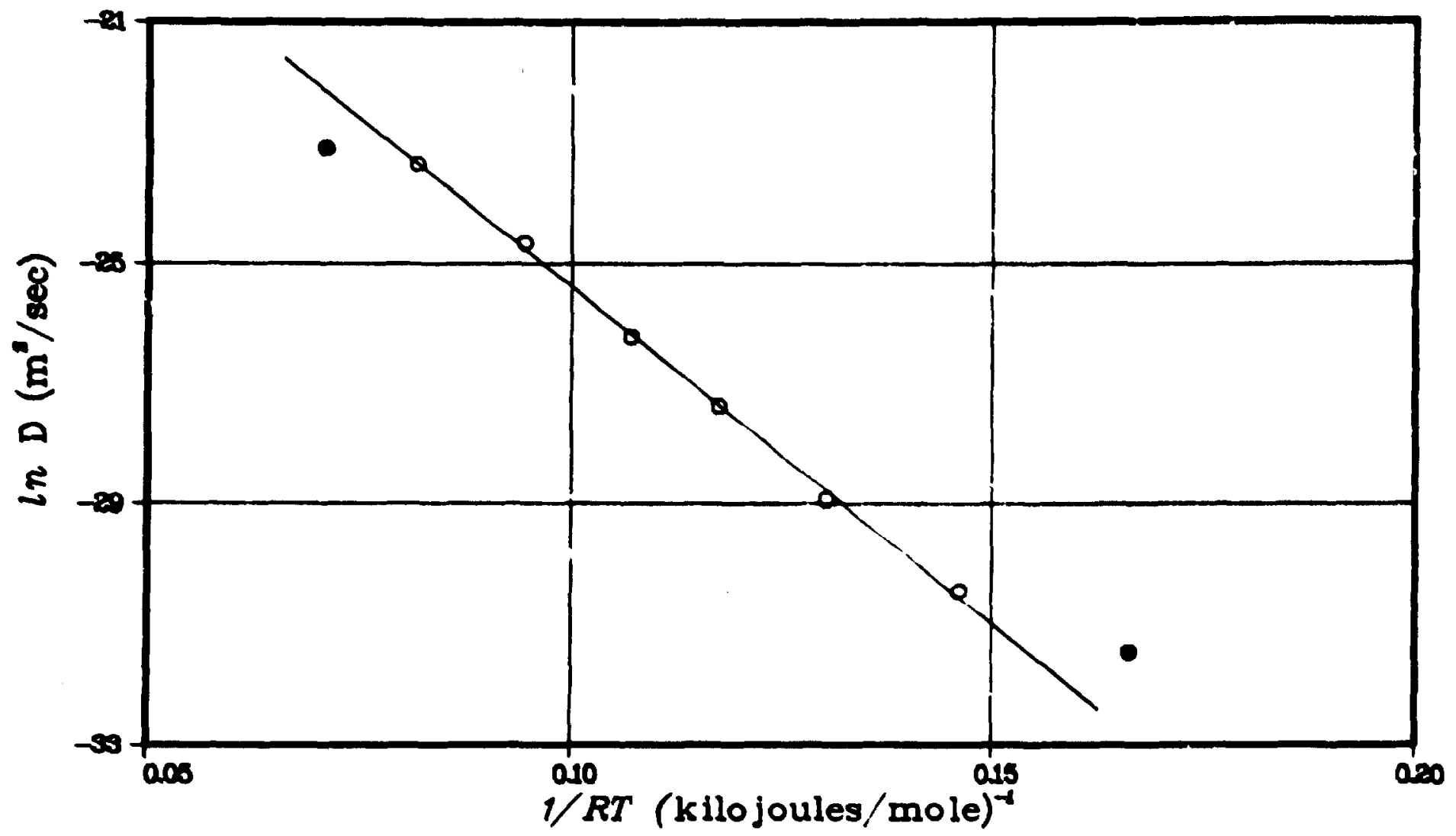

Fig. 3. Plot of $l n$ D vs. 1/RT with Least Squares Line Fi

Showing the Correctness of the Arrhentus Relationship for OR2261IIT Data. 
(se হef. 4;. This data, along with the uptake data for six other fuelparticle bätches (OR2263HT, OR2269HT, J596, J598, J605, and J606), 5 , is analyzed with the data-fitting procedure described ab;ve. The process variables and geometr.cal parameters of these six batches are reported in Ref. 7. of the six, the four $J$ prefixed batch numbers were originally labeled by $A$ prefixes. The $J$ numbers, which are used in Ref. 5, were assigned after the original $A$ numbered batches were annealed for 30 minutes at $1800^{\circ} \mathrm{C}$. The correspondence between the $A$ numbers and $J$ numbers is as follows: A770 becomes J596; A772 becomes 1598 ; A786 becomes $\mathrm{J605}$; and $\mathrm{A787}$ becomes $\mathrm{J606}$. The results are reproduced in Table 2. The IO column labels the fuei-particies batches as identified in Ref 5 with OR2261/XX indicating the particles which received the extra $2000^{\circ} \mathrm{C}$ vacuum anneal and 0R2261/Ne indicating the neon permeation data. Hereafter, the OR226IHT helium permeation data discussed above will be referred to as $0 R 2261 / \mathrm{He}$. All data presented here, with the exception of OR2261/Ne, is in regard to the helium permeation of the fuel-particles; all uptake measurements are the anneals at a pressure of \$8KPa. An Arrhenius re ationsnip is assumed, and the diffusivities of Table 2 are fitted by a least squares method as described above yielding the values of $\mathrm{ZnO}_{\mathrm{c}}$ and $\mathrm{Q}$ shown in Table 3. Also shown in Table 3 are the average values of $r_{i}$ and $s$ along with the 0R2261/He results for convenience.

Figures $4 a$ and $4 b$ show the data and theoretical fits for two of the fuel-particle batches of Ref. 5. Figure 4 a is for fuel-particle batch $\mathrm{J} 596$ annealed at $550^{\circ} \mathrm{C}$ and Figure $4 \mathrm{~b}$ is for $\mathrm{J598}$, also at $550^{\circ} \mathrm{C}$. Note that 3596 has a much lower diffusion rate than J598; the time axis in Figure $4 \mathrm{a}$ is longer, but yet the curve rises much more slowly than in Figure $4 \mathrm{~b}$. Also note that the error bars are larger and that the data is 
Table 2. Fitted Diffusivities and Porosities for Additional Experimental Measumements of Refs. 4 and 5. (See Text)

\begin{tabular}{|c|c|c|c|c|}
\hline ID & $T\left({ }^{\circ} \mathrm{C}\right)$ & $D\left(\mathrm{~m}^{2} / \mathrm{s}\right)$ & $n$ & $\varepsilon$ \\
\hline OR2261/Ne & $\begin{array}{r}850 \\
1000 \\
1200\end{array}$ & $\begin{array}{l}6.672 \times 10^{-15} \\
7.197 \times 10^{-1-} \\
6.863 \times 10^{-13}\end{array}$ & $\begin{array}{l}0.0471 \\
0.0428 \\
0.0394\end{array}$ & $\begin{array}{l}0.195 \\
0.194 \\
0.195\end{array}$ \\
\hline OR2261/XX & $\begin{array}{r}550 \\
1000\end{array}$ & $\begin{array}{l}1.301 \times 10^{-14} \\
8.141 \times 10^{-12}\end{array}$ & $\begin{array}{l}0.0888 \\
0.0610\end{array}$ & $\begin{array}{l}0.195 \\
0.183\end{array}$ \\
\hline J550 & $\begin{array}{r}550 \\
750 \\
1000 \\
1200\end{array}$ & $\begin{array}{l}1.133 \times 10^{-16} \\
2.606 \times 10^{-13} \\
5.041 \times 10^{-12} \\
1.005 \times 10^{-11}\end{array}$ & $\begin{array}{l}0.00929 \\
0.0103 \\
0.00874 \\
0.0337\end{array}$ & $\begin{array}{l}0.104 \\
0.101 \\
0.104 \\
0.0970\end{array}$ \\
\hline$J 598$ & $\begin{array}{r}450 \\
550 \\
750 \\
1000\end{array}$ & $\begin{array}{l}4.040 \times 10^{-14} \\
3.438 \times 10^{-13} \\
6.186 \times 10^{-12} \\
1.132 \times 10^{-13}\end{array}$ & $\begin{array}{l}0.0256 \\
0.00943 \\
0.0164 \\
0.0135\end{array}$ & $\begin{array}{l}0.112 \\
0.115 \\
0.119 \\
0.118\end{array}$ \\
\hline $\mathrm{J} 605$ & $\begin{array}{r}550 \\
750 \\
1000\end{array}$ & $\begin{array}{l}1.385 \times 10^{-13} \\
3.529 \times 10^{-13} \\
1.375 \times 10^{-13}\end{array}$ & $\begin{array}{l}0.00924 \\
0.241 \\
0.00380\end{array}$ & $\begin{array}{l}0.107 \\
0.101 \\
0.105\end{array}$ \\
\hline$J 606$ & $\begin{array}{r}550 \\
750 \\
1000\end{array}$ & $\begin{array}{l}1.577 \times 10^{-14} \\
2.613 \times 10^{-13} \\
1.405 \times 10^{-11}\end{array}$ & $\begin{array}{l}0.0905 \\
0.172 \\
0.0261\end{array}$ & $\begin{array}{l}0.109 \\
0.103 \\
0.103\end{array}$ \\
\hline OR2263 & $\begin{array}{r}550 \\
750 \\
1000\end{array}$ & $\begin{array}{l}4.710 \times 10^{-14} \\
3.182 \times 10^{-13} \\
2.653 \times 10^{-11}\end{array}$ & $\begin{array}{l}0.0293 \\
0.181 \\
0.0156\end{array}$ & $\begin{array}{l}0.196 \\
0.185 \\
0.186\end{array}$ \\
\hline OR2269 & $\begin{array}{r}450 \\
550 \\
750 \\
1000\end{array}$ & $\begin{array}{l}2.381 \times 10^{-13} \\
1.003 \times 10^{-12} \\
2.581 \times 10^{-11} \\
5.841 \times 10^{-11}\end{array}$ & $\begin{array}{l}0.00452 \\
0.00957 \\
0.00798 \\
0.0512\end{array}$ & $\begin{array}{l}0.202 \\
0.202 \\
0.215 \\
0.214\end{array}$ \\
\hline
\end{tabular}


Table 3. Arrhenius Coefficients, Activation Energies, and Averaged Porosities

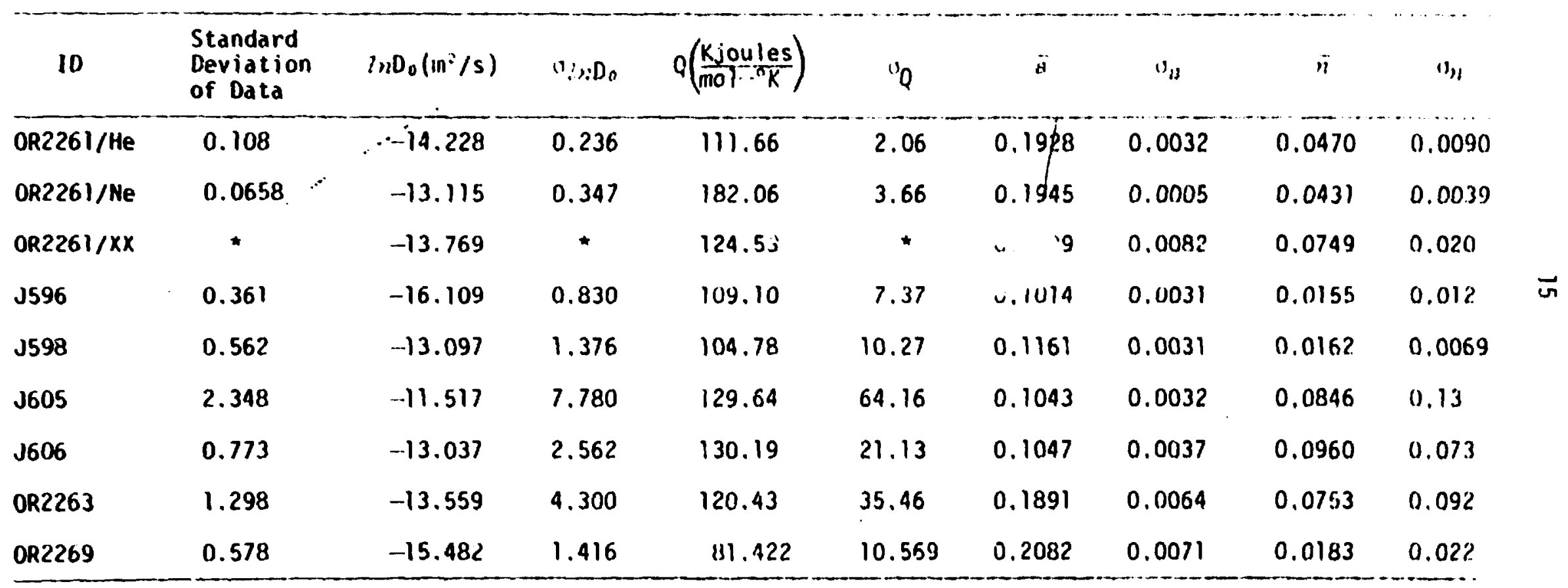

*Data at only two temperatures was availabie thus yielding a "perfect" least squares fit having zero standard deviation. 


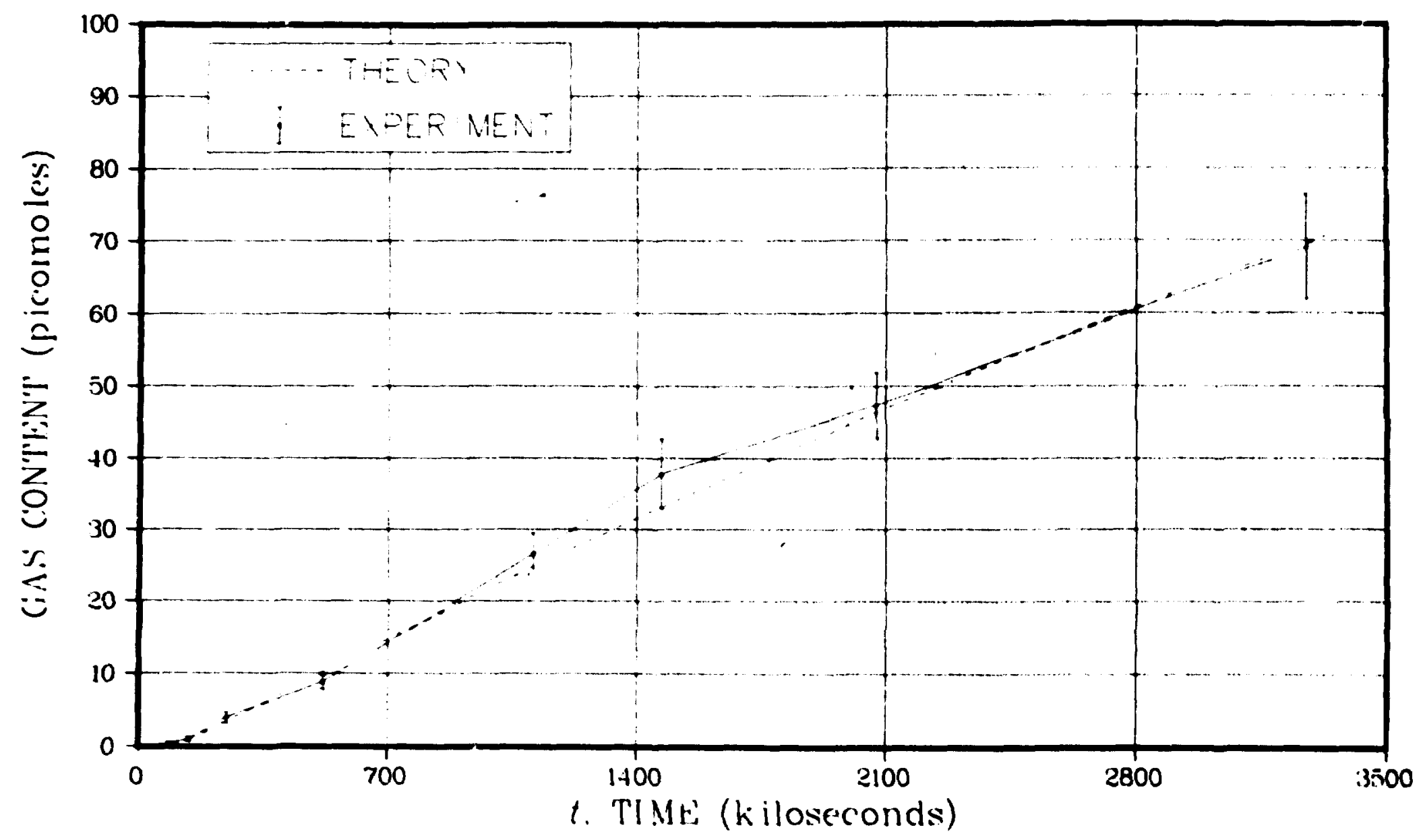

Fig. 4a. Experimental Data and Fitted Curve for 3596 Fuel-Particles Annealed in Hel ium at $550^{\circ} \mathrm{C}$. 


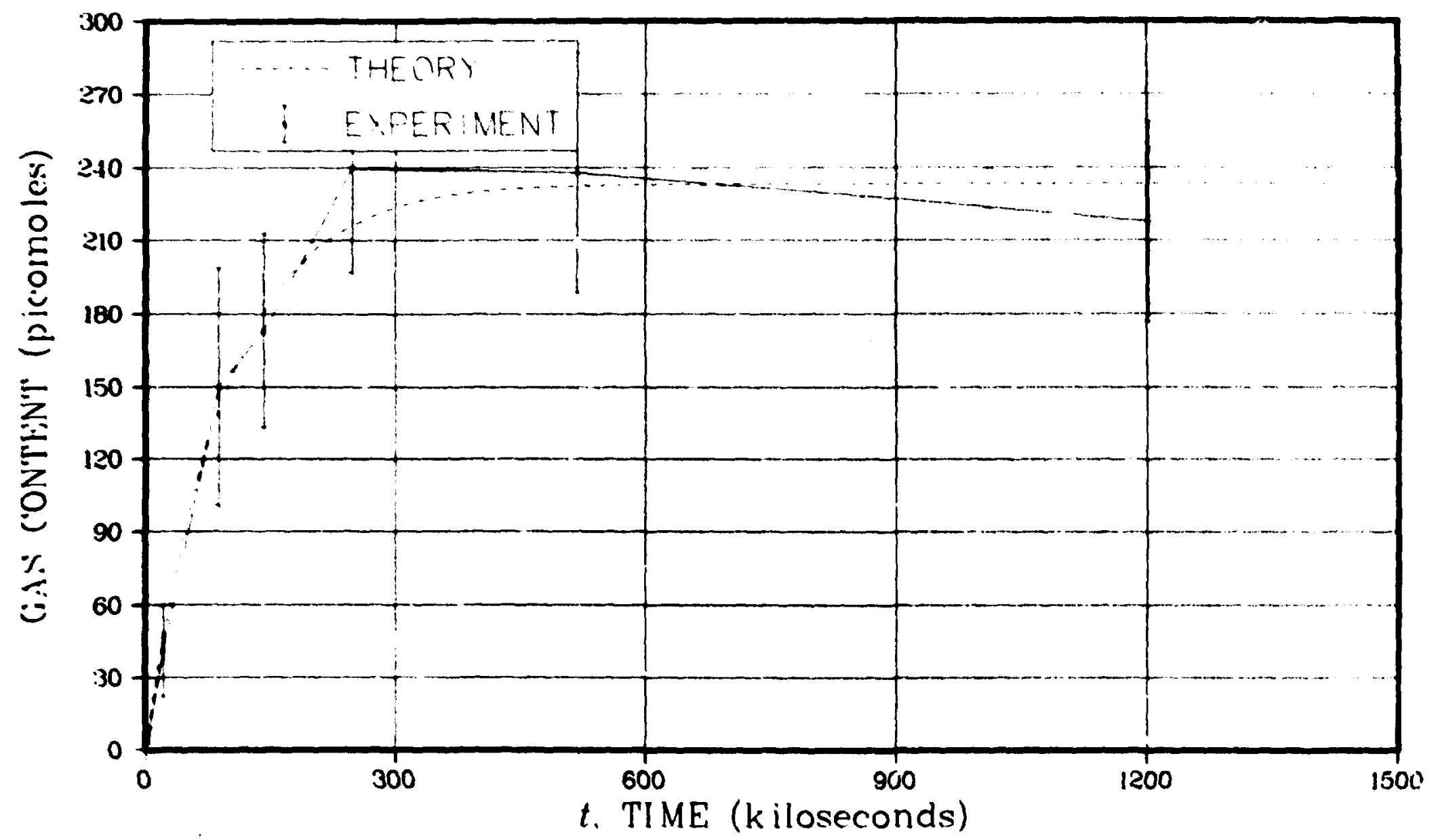

Fig. 4b. Experimental Data and Fitted Curve for $J 598$ Fuel-Particles Annealed in Helium at $550^{\circ} \mathrm{C}$. 
generally more scuttered than the OR2261/He data of Figure 1 . Having been measured at more temperature isotherms, and having more data points along each isotherm and smaller error bars for each data point, the OR2261/He data is jetter than the rest of the data of Refs. 4 and 5 , and therefore the $0 R 2 \hat{c} 61 /$ He fits are the most reliable.

The final : tep in our fitting procedure is to force the diffusivities D to lie on a lile obeying the Arrhenius re?ationship and to force the inner porosity $\therefore$, which is reated to $\gamma$, to be constant for each fuel-particle batch. Thus, using the Arrhenius coefficients and averaged inner porosities of iable 3, each set of data in the 10 column of Table 3 is fitted again with the theoretical uptake model allowing only the parameter $q$ to vary. With $s$ known, the outer porosity $n$ is proportional to $g$ so all the variability falls on $n$. The fitted outer Dorosities are shown in Table 4. The pornsity should be constant among particles of the same batch so these $n$ 's are averaged with the results appearing in Table 5. For convenience Table 5 also reproduces the Arrhenius coefficients and the inner porosities shown in Table 3.

It must be noted that the values given for $\ln \mathrm{D}_{0}$ and $Q$ in Tables 3 and 5 are not the true values but only estimates determined from the linear least squares fit. In the process of linearizing Eq. (5) by taking its logarithm, it is necessary to assume that the statistical errors are multiplicative rather than additive. Then, in applying a linear fit to the linearized equation,

$$
\ln D=\ln D_{0}-Q / R T,
$$

it is implicftly assumed that $\mathrm{InD}_{\mathrm{n}}$ and $Q$ are nomally distributed random variables with variances $\sigma^{2}{ }_{2 n} D_{0}$ and $\sigma_{Q}^{2}$ respectively. Since $Q$ is normally distributed, the best estimate for the activation energy is simply the ? shown in the tables. However, the normal distribution of $\ln D_{0}$ means 
Table 4. Fitted Outer Porosity $n$ hile Holding all Other Parameters Constant

\begin{tabular}{|c|c|c|}
\hline 10 & $T\left({ }^{\circ} \mathrm{C}\right)$ & $n$ \\
\hline OR2261/He & $\begin{array}{r}450 \\
550 \\
650 \\
750 \\
850 \\
1000 \\
1200 \\
1425\end{array}$ & $\begin{array}{l}0.0384 \\
0.0384 \\
0.0406 \\
0.0+57 \\
0.044 ? \\
0.0515 \\
0.0599 \\
0.0853\end{array}$ \\
\hline OR2261/Ne & $\begin{array}{r}850 \\
1000 \\
1200\end{array}$ & $\begin{array}{l}0.0455 \\
0.0459 \\
0.0380\end{array}$ \\
\hline OR2261/XX & $\begin{array}{r}550 \\
1000\end{array}$ & $\begin{array}{l}0.0892 \\
0.0587\end{array}$ \\
\hline $\mathrm{J} 596$ & $\begin{array}{r}550 \\
750 \\
1000 \\
1200\end{array}$ & $\begin{array}{l}0.00864 \\
0.00981 \\
0.0144 \\
0.0216\end{array}$ \\
\hline$J 598$ & $\begin{array}{r}450 \\
550 \\
750 \\
1000\end{array}$ & $\begin{array}{l}0.0176 \\
0.0192 \\
0.0109 \\
0.0151\end{array}$ \\
\hline$J 605$ & $\begin{array}{r}550 \\
750 \\
1000\end{array}$ & $\begin{array}{l}0.0266 \\
0.00937 \\
0.0120\end{array}$ \\
\hline 3606 & $\begin{array}{r}550 \\
750 \\
1090\end{array}$ & $\begin{array}{l}0.168 \\
0.0509 \\
0.0424\end{array}$ \\
\hline OR2263 & $\begin{array}{r}550 \\
750 \\
1000\end{array}$ & $\begin{array}{l}0.0571 \\
0.0277 \\
0.0322\end{array}$ \\
\hline OR2269 & $\begin{array}{r}450 \\
550 \\
750 \\
1000\end{array}$ & $\begin{array}{l}0.00431 \\
0.00723 \\
0.0162 \\
0.0337\end{array}$ \\
\hline
\end{tabular}


Table 5. Arrhenius Coefficients, Activation Energies, and Averaged Porosities After the Final Fit

\begin{tabular}{|c|c|c|c|c|c|c|c|c|}
\hline 10 & $\ln D_{0}\left(n 1^{2} / s\right)$ & ${ }^{0} \ln \mathrm{D}_{0}$ & $\mathrm{Q}\left(\frac{\mathrm{Kjoules}}{\mathrm{mol}{ }^{\circ} \mathrm{K}}\right)$ & ${ }^{\sigma} Q$ & $i$ & $\sigma_{8}$ & $\pi$ & $o_{n}$ \\
\hline $0 \mathrm{R} 2261 / \mathrm{He}$ & -14.228 & 0.236 & 111.66 & 2.06 & 0.1928 & 0.0032 & 0.0468 & 0.0078 \\
\hline $0 R 2261 / \mathrm{Ne}$ & -13.115 & 0.347 & 182.06 & 3.66 & 0.1345 & 0.00005 & 0.0431 & 0.0014 \\
\hline $0 R 2261 / x X$ & -13.769 & $\star$ & 124.53 & $\star$ & 0.1889 & 0.0082 & 0.0740 & 0.0216 \\
\hline J536 & -16.109 & 0.830 & 109.10 & 7.37 & 0.1014 & 0.0031 & 0.0136 & 0.0059 \\
\hline J598 & -13.097 & 1.376 & 104.78 & 10.27 & 0.1161 & 0.0031 & 0.0157 & 0.0036 \\
\hline J605 & -11.517 & 7.780 & 129.64 & 64.16 & 0.1043 & 0.0032 & 0.0160 & 0.0093 \\
\hline J606 & -13.037 & 2.562 & 130.19 & 21.13 & 0.1047 & 0.0037 & 0.0870 & 0.0699 \\
\hline $0 R 2263$ & -13.559 & 4.300 & 120.43 & 35.46 & 0.1891 & 0.0064 & 0.0390 & 0.0158 \\
\hline OR2269 & -15.482 & 1.416 & 81.422 & 10.569 & 0.2082 & 0.0072 & 0.0154 & 0.0132 \\
\hline
\end{tabular}

* see note at end of Table 3 . 
that $D_{0}$ follows what is called a log norma? distribution. From statistical considerations of the log normal distribution, a simple application of the exponential function to the estimate $2 \mathrm{nD}_{0}$ yields an estimate for $D_{0}$ thich is biased by the factor $\exp \left(\sigma_{\ln D_{0}}^{2} / 2\right\}$. When the standard error in $\mathrm{ZnD_{0 }}$ is large, the biasing factor is quite significant and must be accolinted for by the formula

$$
\hat{D}_{0}=\exp \left\{2 n D_{0}\right\} \times \exp \left\{-\sigma_{2 n D_{0}}^{2} / 2\right\} .
$$

Here, the symbol " over $D_{0}$ is used to indicate "the best estimate of." In like manner the best estimate for the standard error in $\hat{D}_{0}$ is given by

$$
\hat{\sigma}_{\hat{D}_{0}}=\exp \left\{\ln \left[1_{0}\right\} \times \sqrt{\exp \left\{\sigma^{2}{ }_{2 n D_{0} \mid}-1\right.}\right.
$$

When the standard error in $2 n D_{0}$ is large, the standard error in $\hat{D}_{0}$ is also large. The standard errors for $2 n D_{0}$ tabulated in Table 5 are significant ror particle batches other than OR2261, and this fact, dlong with Eqs. (6) and (7), must be noted by the reader.

The large standard errors for $2 \mathrm{r}_{0}$ and the high variability of $n$ for all except particle batch 0R2261 are speculated to arise from two sources. The primary scirce of error is the real macroscopic particleto-particle variation in tive geometric dimensions of the particles., 7 . This variability is relatively small for the OR2261/HT particles and is refiected in the good fits for OR2261/lle and OR2261/Ne. The good fit for 0R2261/He also results from the relatively large number of isotherms at which data were measured for this particle batch. For the other particle batches the real particle-to-particle variability is greater, the number of fsotherms is less, and the dati avaflable for each isotherm 
22

are fewer and have larger errors. All these factors combine to result in poorer its for particle hatches other thar OR2261. Those particleto-particle deviations arise from ronunirorm coating thicknesses for particles in the same batch and a lack of sphericity of the particles. Cracks in the outer coating of the particles would also contribute to ?large errors in the data since these cracks would allow vastly higher diffusion rates. However, the particles were carefully manufactured in order to prevent cracks, and the fraction of articles with cracked coatings is known to be quite low. The manufacture, geometry, and uniformity of the fuel-particles are discussed in Refs. 1 and 7 


\section{CONCLUSION}

The theoretical expression derived by Reeves and Tolliver 6 for the gas content of the spherical core of - dense spherical shell after the diffusion of gas through the shell has been used to make a numerical calculation of the gas content of the core of HTGR biso-coated fuel particles. The numerical calculasion has been combined with a data-fitting program and experimental measurements of the gas content of HTGR fuelparticles to determine the values of the physical parameters $D, n$, and $s$ of the fuel-particles for several different temperatures. The results have been reported and sample plots of the experimental data and fitted curves have been shown. An Arrhenius reiationship between the absolute temperature and the diffusivity $D$ has been assumed and the activation energy $Q$ reported for each batch. The values of $2 n D_{0}$ have been reported along with instructions for obtaining the best statistical estimate for the coefficient $D_{0}$ and $i$ ts stardard error from the quantities $\ln _{n} D_{0}$ and $\sigma_{2 n D_{0}}$. The theoretical fit for OR2261/He is quite good, having standard errors in the activation energy and $2 n D_{0}$ of less than $2 \%$. However, for fuel-particle batches other than OR2261, the standard errors ir $\ln D_{0}$ are large, leading to wide confidence limits on the value of $D_{0}$. These large standard errors are primarily due to wide confidence rimits on the data itself due to the particle-to-particle geometric variability. To a lesser extent these large uncertainties are contributed to by the lack of data since only a fex: isotherms with only a few points per isotherm were measured for these particle batches. A better rit ano more reliable results would be obtained by using an optimizing computer code with the absolute temperature as well as the time as 
independent. variables in the expression for the gas content of a fuelparticle. By explicitly including the temperature dependence, all of the data for each fuel-particle batch could be used, and the Arrhenius coefficients $D_{0}$ and $Q$, as well as quantities $\gamma$ and $q$, could be selfconsistently determined for all of the isotherms for each batch. By coupling all of the data for each isotherm, the uncertainties due to fewer isotherms and fewer points for all batches except 0R2261/He would be reduced but not eliminated. Hore data at more isotherms would obviously be desirable. Of course this procedure would not ol iminate the major source of errors - that due to the particle-toparticle geometric variability. These errors can only be reduced by the careful manufacture of uniform particle batches. 


\section{REFERENCES}

1. Lackry, H. J., Stinton, D. P., and Sease, J. D., "Improved Gas Cistributor for Coating High-Temperature Gas-Cooled Reactor Fuel-Particles," thuciear Technology, 35, 2, pp. 227-37, (September 1977).

2. Morgan, C. S., and Powell, G. L., "Preliminary Examination of the Helium Permeability of Pyrocarbon Coatings,' Hersech Techology, $35,337,(1977)$.

3. Morgan, C. S., Eatherly, K. P., and Powell, G. L., "Inert Gas Permeability of Pyrocarbon Coatings," Proceedings of the 13th Annuat Carbon Conference, University of California at Irving, (July 1977).

4. Powell, G. L., Inert Gas Permeability of High-Temperature Gas-Cooled Reaftor Coated Fuel-Particles, (Y/DA-7885) (1978).

5. Powell, G. L., Helizon Permeability of Biso High-Temperature Gastrooled Reactor (HTGR) Fuel-Particles, (Y/DA-8035) (1978).

6. Reeves, M., and Tolliver, J. S., Transient Diffusion Through $A$ Spherical Shell into its Finite Spherical Core, ORNL/CSD/TM-60, (1979).

7. Stinton, D. P., Lackey, W. J., and Thiele, B. A., Influence of Process Variubles on Permeability and Anisotroky of Biso-coated iTh Fuel-Particles, ORNL/TM-6087 (1977). 